\title{
Visual behavior of the Mongolian gerbil (Meriones unguiculatus)'
}

D. D. THIESSEN, GARDNER LINDZEY, STEVE BLUM, ANN TUCKER, AND HAROLD C. FRIEND, DEPARTMENT OF PSYCHOLOGY, UNIVERSITY OF TEXAS, Austin, TeX. 78712

The Mongolian gerbil, Meriones unguiculatus, appears to be deficient in depth perception. Whereas C57BL/6J mice show a predominance of shallow responses on a visual cliff (e.g., $100 \%$ of initial responses is to the shallow side), gerbils show random behavior (e.g., $56 \%$ of initial responses is to the shallow side). Gerbils are not blind, however, as they show a strong preference for darkness when allowed a choice, and their circadian activity cycle can be readily entrained with the light cycle.

Our interest in the visual behavior of the gerbil arose from the incidental observation that the gerbil often falls off solid surfaces and high places as if it were insensitive to depth cues. In this paper we report on the animal's visual cliff response and its general responsiveness to visual cues. The $\mathrm{C} 57 \mathrm{BL} / 6 \mathrm{~J}$ mouse was used as a comparative species because of the existing literature on its visual behavior.

\section{EXPERIMENT 1}

Visual Cliff behavior. Fifty gerbils ( 25 of each sex) were tested on a visual cliff apparatus and compared with nine male and eight female mice. Gerbils ranged in age from 76 to 159 days of age and the mice were between 234 and 253 days of age. The cliff apparatus is a double sided box $77 \mathrm{~cm} \mathrm{sq}$ and 41 $\mathrm{cm}$ deep. Walls $61 \mathrm{~cm}$ high surround the apparatus. Both the shallow and deep sides are covered with vinyl $1.28 \mathrm{~cm}$ black and white checkerboard cloth. Glass covers both sides, and a centerboard $3.84 \mathrm{~cm}$ high spearates the shallow and deep sides. Because of the size differences between the species, the centerboard is $10.24 \mathrm{~cm}$ wide for the gerbil and $2.56 \mathrm{~cm}$ wide for the mouse. The animals were given 10 trials each with $60 \mathrm{sec}$ intertrial interval. Species and sexes were run in a partially counterbalanced order, and the apparatus was cleaned between animals and between trials when necessary to avoid possible olfactory cues. The cliff was rotated $180 \mathrm{deg}$ after each five trials. Twenty-four hours prior to testing vibrissae were clipped to prevent tactual recognition of the glass.

Figure 1 shows the per cent and distribution of shallow responses for both species. Sixty-five per cent of the mice responded to the shallow side on all 10 trials, whereas only $4 \%$ of the gerbils responded to the shallow side on all 10 trials. The modal response for the gerbil was only six out of 10 responses to the shallow side. On the first trial the differences were even more striking. All mice initially responded to the shallow side, whereas only $56 \%$ of the gerbils made initial shallow responses. No sex differences were evident. As a result of these tests we began to question whether the gerbil had any vision at all and might have a condition analogous to retinal degeneration reported for the mouse (Sidman \& Green, 1965). Several tests revealed that this is not the case.

\section{EXPERIMENT 2}

Preference for Darkness. Thirty-four adult gerbils and 34 adult C57BL/6J mice (17 of each sex for each species) were each allowed a $20 \mathrm{~min}$ period to

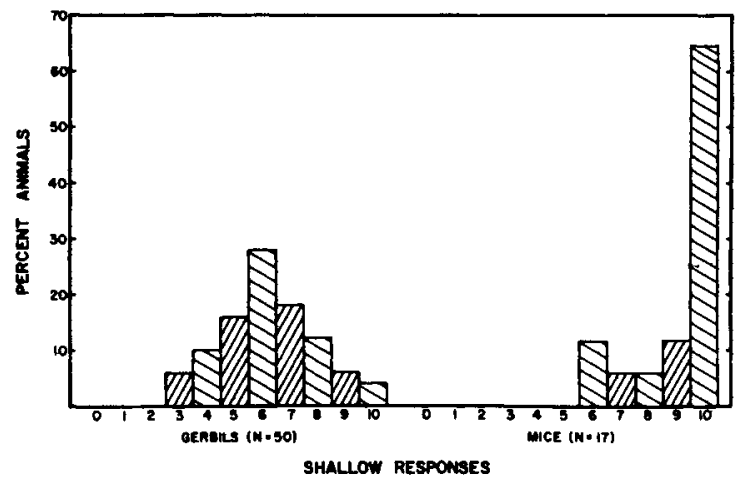

Fig. 1. Distribution of responses on visual cliff. Per cent of gerbils and mice responding to shallow side during 10 trials.

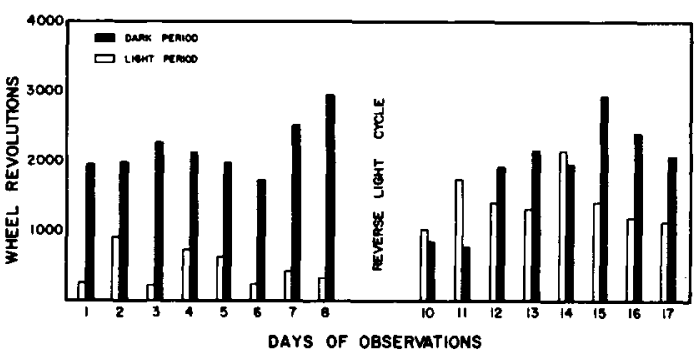

Fig. 2. Wheel revolutions of gerbil during $12 \mathrm{~h}$ dark and $12 \mathrm{~h}$ light periods before and after reversal of light cycle.

locomote over a horizontal area $82 \mathrm{~cm}$ sq divided into a dark and a light half. Walls $31 \mathrm{~cm}$ high surrounded the apparatus. The light side $(62 \mathrm{ft} \mathrm{cp})$ was obtained by using florescent lamps under a milkglass sheet, whereas the dark side consisted of a black sheet of glass. Temperature was equal on the two sides. Each animal was tested individually, and the time spent on the dark side was recorded. No other light was present in the test room. To control for possible tactual differences between the two sides that might bias the response, 10 additional gerbils and 10 additional mice (equal numbers of each sex) were tested on the apparatus with no lights except a dim red observation light.

In the experimental situation both gerbils and mice showed a strong preference for the dark side, with $70 \%$ of the 20 min period spent on the dark side. Both species showed no preference for either side under the total dark control condition, with $52-54 \%$ of the 20 min period spent on the dark glass. The experimental and control conditions differed significantly for both gerbils and mice $(t=7.84$ and 6.38 , respectively; $p<.001)$. No sex differences were noted on this problem. Clearly under these conditions gerbils, as well as mice, discriminate between dark and light and prefer the former.

\section{EXPERIMENT 3}

Circadian Activity. As a final test of sensitivity to light, 20 adult male gerbils were observed as pairs for activity in 10 running wheels under both the usual $12 \mathrm{~h}$ light and $12 \mathrm{~h}$ dark cycle, and after a reversal of the light cycle. After 27 days of acclimation to the wheels, revolutions were recorded for each $12 \mathrm{~h}$ during an eight day period. The light cycle was then reversed and activity was again recorded for each $12 \mathrm{~h}$ period during the next eight days. Figure 2 indicates a strong nocturnal activity that is easily entrained with a reversal of the light cycle. Figure 3 illustrates the hourly variations in gerbil activity with a clear peak around 1:30 AM. The gerbil is obviously sensitive to differences in light intensity and makes appropriate behavioral adjustments. Recently we have recorded electroretinograms from two gerbils that provide physiological verification of the gerbil's visual sensitivity.

\section{DISCUSSION}

The question remains why the gerbil is deficient in cliff behavior but otherwise visually capable. It is not easy to define the critical stimulus environment for the gerbil, since relatively little is

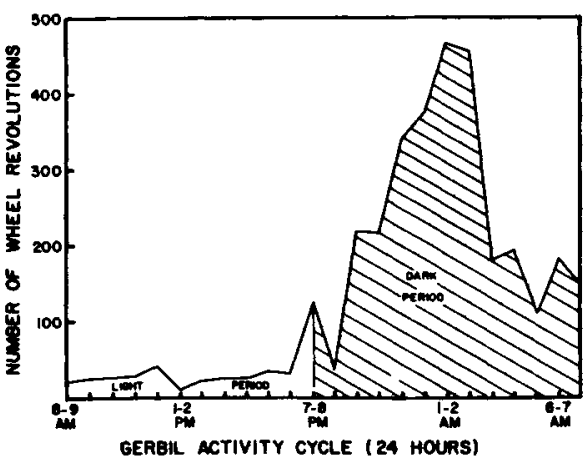

Fig. 3. Wheel revolutions of gerbils during $224 \mathrm{~h}$ period. 
known about its ecology and behavior. It is possible that in this burrowing form the desert environment has not favored selection for cliff avoidance. If this is the case, we have a functionally decorticate species as far as depth recognition is concerned. A similar peculiarity of cliff performance has been reported in the Egyptian gerbil, Gerbillus gerbillus. This species will readily cross over from the deep to the shallow side of a visual cliff, although the initial response is always to the shallow side (Routtenberg \& Glickman, 1964). With $M$. unguiculatus, the species in this study, the explanation may involve an undetermined emotional factor. The average latency for a cliff response is $12 \mathrm{sec}$ for the gerbil compared to $120 \mathrm{sec}$ for the mouse. It is possible that excitability is so great for the gerbil that it does not attend to differential cues. A comparable situation can be induced in the rat (Rhosen \& Ison, 1964). However, chlorpromazine variations in height of stepdown platform and alterations in apparatus lighting did not change the response.

\section{REFERENCES}

ROSEN, A. J., \& ISON, J. R. Effects of deprivation level, reinforcement conditions, and continued testing on visual cliff performance. J. comp. physiol Psychol., 1964, 57, 471-472.

ROUTTENBERG, A., \& GLICKMAN, S. E. Visual cliff behavior in undomesticated rodents, land and aquatic turtles, and cats (Panthers). $J$. comp. Physiol. Psychol, 1964, 58, 143-146.

SIDMAN, R. L., \& GREEN, M. C. Retinal degeneration in the mouse; location of the rd locus in linkage group XVII. J. Heredity, 1965, 56, 23-29.

\section{NOTE}

1. This research was supported in part by NIMH Grant MH 14076-01 and NIMH Research Development Award MH-11, 174-01 awarded to Delbert D. Thiessen. 